\title{
ASSOCIATION OF PLATELET INDICES WITH DISEASE ACTIVITY IN RHEUMATOID ARTHRITIS
}

\author{
Shuba $N^{1}$, Praba $V^{2}$, Prithiviraaj $P^{3}$
}

${ }^{1}$ Associate Professor, Department of Physiology, PSG IMS and R, Coimbatore, Tamilnadu, India.

2 Associate Professor, Department of Pathology, Coimbatore Medical College, Coimbatore, Tamilnadu, India.

3IIIrd Year MBBS Student, Coimbatore Medical College, Coimbatore, Tamilnadu, India.

\section{BACKGROUND}

ABSTRACT

Rheumatoid Arthritis (RA) is a chronic autoimmune inflammatory disease of unknown aetiology that mainly affects peripheral joints in a symmetric pattern. Prevalence of RA is approximately $1 \%$ worldwide, being two to three times more common in women than men. Effective management in RA requires close monitoring of disease activity. Platelet activation is an important event in synovial inflammation, but very few studies have used platelet indices to assess inflammation.

Thus, the aim of the study was to correlate the platelet indices (platelet count, mean platelet volume and platelet distribution width) with disease activity in Rheumatoid Arthritis.

\section{MATERIALS AND METHODS}

This descriptive comparative study was conducted among 60 RA patients and 30 healthy controls within the age group of 30 to 70 years. Every consecutive RA patient who attended the Rheumatology Outpatient Department was included in the study. The severity of RA was assessed by the Disease Activity Score Calculator for Rheumatoid Arthritis (DAS-28). The platelet indices assessed in the study include platelet count, Mean Platelet Volume (MPV) and Platelet Distribution Width (PDW) obtained from their CBC report. The study population was divided into three groups. Group I (Moderate disease activity) with DAS-28 score of 3.2-5.1; Group II (High disease activity) with DAS-28 score above 5.1. Thirty patients in Group I and thirty in Group II were taken for the study. Group III: 30 healthy controls who attended the Master Health Check-Up Department. Data analysis was done by using SPSS software and independent t-test. $\mathrm{P}$ value $<0.05$ was taken as statistically significant.

\section{RESULTS}

There was statistically significant increase in platelet count, decrease in MPV and PDW in high-grade RA patients when compared with normal individuals $(p=0.004, p=0.001, p=0.019$ respectively). We also found similar statistical significance between high and moderate grade RA patients ( $p=0.001$ for platelet count, $p=0.007$ for MPV and $p=0.012$ for PDW).

\section{CONCLUSION}

Our study suggests that platelet indices can be considered as inflammatory markers for disease activity in RA. However, further studies with larger number of patients are warranted to cross validate our findings.

\section{KEY WORDS}

Rheumatoid Arthritis, Platelet Indices, DAS 28.

HOW TO CITE THIS ARTICLE: Shuba N, Praba V, Prithiviraaj P. Association of platelet indices with disease activity in rheumatoid arthritis. J. Evolution Med. Dent. Sci. 2018;7(36):3940-3945, DOI: 10.14260/jemds/2018/881

\section{BACKGROUND}

Rheumatoid Arthritis is a chronic autoimmune inflammatory disease characterised by tenderness, swelling and stiffness of the joints with progressive destruction of cartilage and bone.[1] RA affects approximately $0.92 \%$ of the adult population of India with 20 to 40 new cases per lakh population every year[2] and is two to three times more common in women than men as other autoimmune diseases. ${ }^{[3]}$

Early diagnosis and aggressive therapy can usually prevent permanent disability and improve the quality of life.[2] Effective management in RA requires close monitoring of disease activity.

'Financial or Other Competing Interest': None.

Submission 23-07-2018, Peer Review 17-08-2018,

Acceptance 23-08-2018, Published 03-09-2018.

Corresponding Author:

Dr. Shuba N,

2F, Mayflower Brookefields Apts.,

62-A, Krishnasamy Road,

R. S. Puram, Coimbatore-641002, Tamilnadu, India.

E-mail: shubaphysio@gmail.com

DOI: $10.14260 /$ jemds $/ 2018 / 881$
To determine the disease activity, clinicians use clinical signs and symptoms, radiological findings and Rheumatoid Factor (RF) values and C-Reactive Protein (CRP) and Erythrocyte Sedimentation Rate (ESR). Other blood tests are required for assessment of systemic involvement (Liver and kidney function) and monitoring of adverse drug events. So far, immune cells were considered to play the central role in RA pathophysiology and until recently platelets have not been expected to have a role in the pathogenesis of the disease. Inflammation creates an imbalance of normal physiological anticoagulant mechanism, induces activation of coagulation system with interleukin- 6 and tumour necrosis factor alpha $(\mathrm{TNF} \alpha)$ thus affecting platelet indices. ${ }^{[4]}$

Dense platelet bodies contain adenosine nucleotides, calcium and serotonin that exert effects in the initial phase of inflammation. They release pre-stored inflammatory mediators and can also produce eicosanoids such as thromboxane $\mathrm{A}_{2}$, prostaglandin $\mathrm{F}_{2} \alpha\left(\mathrm{PGF}_{2} \alpha\right)$ and $\mathrm{PGE}_{2}$, to regulate inflammatory response and can synthesize peptide mediators such as interleukin (IL)- $1 \beta$ on stimulation. ${ }^{[5,6]}$

From the 1950s, many attempts were made to design a disease activity measurement tool. Tools available are in the form of patient questionnaires, joint counts or lab tests. Most 
of the American College of Rheumatology (ACR)-approved measurement tools combine one or more of these elements. For example, the Disease Activity Score Calculator for Rheumatoid Arthritis Scale (DAS-28) combines a joint count and a lab test (Either the ESR or CRP). These data are plugged into a formula, which produces a number between 0 and 10 that reflects how well RA is controlled.[7,8]

Studies relating clinical utility of platelets in patients with RA have produced controversial results. Platelet indices are calculated during routine blood analysis along with Complete Blood Count, but these are generally not considered by clinicians. Mean Platelet Volume (MPV) and platelet counts are inversely associated, so that the total platelet mass remains approximately constant.[9] The aim of our study is to prove the hypothesis that there is association of platelet indices (Platelet count, Mean Platelet Volume (MPV) and Platelet Distribution Width (PDW)) with diseases activity in Rheumatoid Arthritis.

\section{MATERIALS AND METHODS}

This was a descriptive, comparative, hospital-based study conducted on 30 moderate disease activity RA patients, 30 severe disease activity RA patients and 30 healthy controls. The study was conducted at Coimbatore Medical College Hospital after obtaining written informed consent from the subjects and obtaining clearance from the Institutional Human Ethics Committee.

\section{Sample Size}

Sample size calculation was done for 2 groups. Calculation of sample size was done by using Open Epi software version 3.01 , by using simplified formula for difference in means of power $80 \%$ and confidence interval $95 \%$ and substituting mean \pm SD values of parameters of platelet indices of Rheumatoid arthritis patients and controls obtained by study done by Yildirim A et al[10] as shown below.

Software uses the following Formula to Calculate Sample Size-

$$
n=\frac{2 \sigma^{2}\left(Z_{\beta}+Z_{\alpha / 2}\right)^{2}}{\left(d^{*}\right)^{2}}
$$

\section{Where-}

$\mathrm{n}=$ Sample size in each group $\sigma=$ Standard deviation of the outcome variable

$\mathrm{d}=$ difference in means

$\mathrm{Z}_{\beta}=$ Corresponds to desired power $(0.84=80 \%$ power $) \mathrm{Z}_{\alpha / 2}=$ Corresponds to two-tailed significance level (1.96 for $\alpha=.05$ )

Mean difference for MPV between cases and controls was 0.7 and mean difference for PDW between cases and controls was 2.59 .

SD for MPV was 0.9 and for PDW was 1.8.

We obtained sample size of 29 in each group for MPV and 21 in each group for PDW.

We made the following comparisons using unpaired t-test using SPSS software, which has 30 subjects in each group: i.e. in ratio $1: 1$. a) Between normal persons and moderate disease activity RA.

b) Between normal persons and severe disease activity RA.

c) Between moderate disease activity and severe disease activity RA.

Except one comparison, i.e. between normal persons (30) and RA patients (60) in the ratio of $1: 2$, which is applicable for comparison purpose.

\section{Sampling Method}

- All consecutive RA patients satisfying inclusion and exclusion criteria attending Rheumatology OP were taken as cases for study till we got 30 in moderate disease activity and 30 in severe disease activity RA.

- All consecutive normal healthy persons attending Master Health Check-Up Department were taken as controls for study till we got 30 . Selection of cases and controls were done by convenience sampling method.

\section{Inclusion Criteria}

- Patients of both genders with age group of 30 - 70 years.

- Patients diagnosed with RA as per 2010 American College of Rheumatology criteria, with at least one year duration.

- Known cases of diabetes and hypertension under control.

\section{Exclusion Criteria}

- Patients with other autoimmune diseases such as Systemic Lupus Erythematosus (SLE) and inflammatory bowel disease.

- Patients with malignancies, chronic liver disease, acute or chronic renal failure, cardiac abnormalities and haematological diseases.

- Patients taking drugs altering platelet morphology and patients with history of receiving blood transfusion during the past three months.

- Rheumatoid arthritis patients with DAS-28 score less than 3.2.

The demographic information of the subjects like name, age and sex was recorded. Complete Blood Count [CBC] is routinely done in Rheumatoid Arthritis patients. The platelet indices assessed in the study include platelet count in $10^{9} / \mathrm{L}$, Mean Platelet Volume (MPV) in fL and Platelet Distribution Width (PDW) in fL. Mean Platelet Volume (MPV) is a machine-calculated measurement of the average volume of a single platelet measured in femtolitres (fL) and is typically included in blood tests as part of the CBC. A typical range of platelet volumes is $9.4-12.3 \mathrm{fL}$. These values were obtained from their CBC reports. Both cases and controls were selected according to the inclusion and exclusion criteria.

The severity of Rheumatoid Arthritis was assessed by the Disease Activity Score Calculator for Rheumatoid Arthritis, DAS-28 with 3 variables represented as DAS-28(3).[7,8] DAS$28(3)$ is a commonly used scale for measuring the disease activity of Rheumatoid Arthritis patients that has been proven to show excellent validity, reliability and responsiveness.[11] This scale uses the swollen joint count (number of swollen joints [0-28]), the tender joint count (number of tender joints [0-28]) and Erythrocyte 
Sedimentation Rate (ESR) in $\mathrm{mm} / \mathrm{hr}$ (From the complete haemogram) to generate the DAS-28(3) score from 0 to 9.4. ${ }^{\text {[7] }}$ These parameters were entered in the computer generated DAS-28(3) scale which uses the formula:

$\operatorname{DAS}-28(3)[7,8]=[(0.56 * \sqrt{\mathrm{t} 28})+(0.28 * \sqrt{\mathrm{s} 28})+(0.70 *$ $\ln \{\mathrm{ESR}\})] * 1.08+0.16$

Where $\mathrm{t} 28=$ number of tender joints ranging from 0 to 28 ; $\mathrm{s} 28=$ number of swollen joints ranging from 0 to 28 ; $\ln$ $\{\mathrm{ESR}\}=\log _{\mathrm{e}}\{\mathrm{ESR}\}$

The joints considered for measuring t28 and s28 included the shoulder joints (2), elbow joints (2), wrist joints (2), metacarpophalangeal joints (10), proximal interphalangeal joints (10) of the upper limbs and the knee joints (2) of the lower limbs.

The Rheumatoid Arthritis patients were divided into Two Groups based on the DAS-28(3) score. Thus, the Study Population was divided into Three Groups-

\section{Group I (Moderate Disease Activity)}

Rheumatoid Arthritis patients with DAS-28(3) score of 3.25.1.[7]

\section{Group II (High Disease Activity)}

Rheumatoid Arthritis patients with DAS-28(3) score above 5.1.[7]

30 patients in group I and group II will be taken for the study.

\section{Group III}

Controls consisting of 30 healthy individuals.

The platelet indices (platelet count, MPV and PDW) obtained from CBC reports was compared between moderate and severe RA patients and also between RA patients and controls.

\section{Statistical Analysis}

Data analysis was done by using SPSS software version 18 . Using this software, percentage, mean, standard deviation and $p$-value was calculated by independent t-test for correlation of platelet indices between mild and severe RA, mild RA and controls, severe RA and controls. P-value $<0.05$ was taken as statistically significant.

\section{RESULTS}

Sixty Rheumatoid Arthritis patients were studied including $49(81.67 \%)$ females and $11(18.33 \%)$ males. The 30 healthy controls comprised of $18(60 \%)$ females and $12(40 \%)$ males. The mean age of Rheumatoid Arthritis patients was 47 and that of controls was 41 .

Platelet count, mean platelet volume and platelet distribution width values were compared between normal and RA patients. They were also compared between moderate and severe RA patients, normal and moderate RA, and normal and severe RA patients. Statistical analysis was done by SPSS software version 18 using unpaired t-test. P values $<0.05$ was considered to be statistically significant.

Comparison of Platelet Indices between Normal and Rheumatoid Arthritis Patients

There were 30 normal persons and 60 RA patients. Their platelet count, MPV and PDW were analysed by independent t-test. There was statistically significant increase in platelet count in RA patients when compared with normal persons $(p=0.045)$ and statistically significant decrease in MPV in RA patients when compared with normal persons $(p=0.01)$. There was no statistically significant difference in PDW between RA patients and normal persons.

The mean \pm SD of platelet count in normal persons were $300.07 \pm 113.413\left(\mathrm{x} 10^{9} / \mathrm{L}\right)$ and in RA patients were $345.27 \pm$ $91.792\left(\mathrm{x} 10^{9 / \mathrm{L}}\right)$. The mean \pm SD of MPV in normal persons was $9.333 \pm 0.7312 \mathrm{fL}$ and in RA patients was $8.932 \pm 0.6508$ fL. The mean \pm SD of PDW in normal persons was $11.0 \pm$ $1.1154 \mathrm{fL}$ and in RA patients was $10.635 \pm 1.0460 \mathrm{fL}$.

Comparison of platelet count between RA patients and normal persons

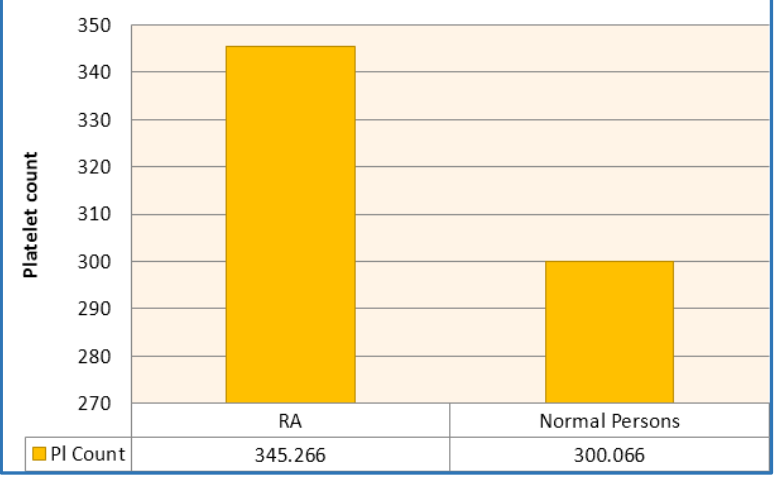

Figure 1

Platelet count $\mathrm{x} 10^{9} / \mathrm{L}$

\section{Comparison of MPV between RA patients and normal persons}

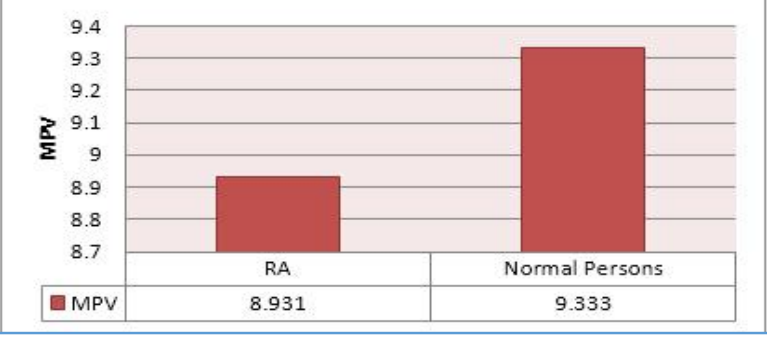

Figure 2

MPV: Mean Platelet Volume in $\mathrm{fL}$

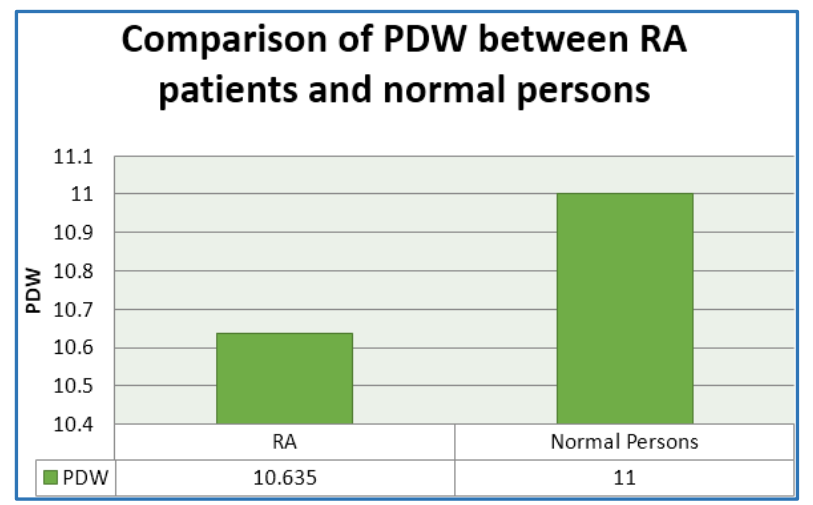

Figure 3

PDW: Platelet Distribution Width in $\mathrm{fL}$ 


\begin{tabular}{|c|c|c|c|}
\hline Parameter & Group & Mean \pm SD & P value \\
\hline \multirow{2}{*}{$\begin{array}{l}\text { Platelet count } \\
\left(\mathrm{x} 10^{9} / \mathrm{L}\right)\end{array}$} & Moderate RA & $\begin{array}{c}304.37 \pm \\
41.751\end{array}$ & \multirow[b]{2}{*}{$0.846(\mathrm{NS})$} \\
\hline & $\begin{array}{l}\text { Normal } \\
\text { Persons }\end{array}$ & $\begin{array}{l}300.07 \pm \\
113.413\end{array}$ & \\
\hline \multirow{2}{*}{$\begin{array}{c}\text { Mean Platelet } \\
\text { Volume(fL) }\end{array}$} & Moderate RA & $9.153 \pm 0.519$ & \multirow[b]{2}{*}{$0.276(\mathrm{NS})$} \\
\hline & $\begin{array}{l}\text { Normal } \\
\text { Persons }\end{array}$ & $9.333 \pm 0.699$ & \\
\hline \multirow{2}{*}{$\begin{array}{c}\text { Platelet } \\
\text { Distribution } \\
\text { Width (fL) }\end{array}$} & Moderate RA & $10.97 \pm 0.838$ & \multirow[b]{2}{*}{$0.907(\mathrm{NS})$} \\
\hline & $\begin{array}{l}\text { Normal } \\
\text { Persons }\end{array}$ & $11.00 \pm 1.115$ & \\
\hline
\end{tabular}

Table 1. Comparison of Platelet Indices between Moderate Rheumatoid Arthritis and Normal Persons

$\mathrm{N}=30$ in both moderate RA and normal persons, values represent the mean $\pm \mathrm{SD}, \mathrm{p}<0.05$ significant, $\mathrm{NS}=$ Not significant.

The platelet count, MPV and PDW of moderate RA patients had no statistically significant difference with those of normal persons.

\begin{tabular}{|c|c|c|c|}
\hline Parameter & Group & Mean \pm SD & P value \\
\hline \multirow{2}{*}{$\begin{array}{l}\text { Platelet count } \\
\qquad\left(\mathrm{x} 10^{9} / \mathrm{L}\right)\end{array}$} & Moderate RA & $\begin{array}{c}304.37 \pm \\
41.751\end{array}$ & \multirow[b]{2}{*}{$<0.001^{* *}$} \\
\hline & Severe RA & $\begin{array}{l}386.13 \pm \\
109.259\end{array}$ & \\
\hline \multirow{2}{*}{$\begin{array}{l}\text { Mean Platelet } \\
\text { Volume (fL) }\end{array}$} & Moderate RA & $9.153 \pm 0.519$ & \multirow[b]{2}{*}{$0.007^{* *}$} \\
\hline & Severe RA & $8.71 \pm 0.699$ & \\
\hline \multirow{2}{*}{$\begin{array}{c}\text { Platelet } \\
\text { Distribution } \\
\text { Width (fL) }\end{array}$} & Moderate RA & $10.97 \pm 0.838$ & \multirow[b]{2}{*}{$0.012^{* *}$} \\
\hline & Severe RA & $10.30 \pm 1.136$ & \\
\hline
\end{tabular}

$\mathrm{N}=30$ in both moderate $\mathrm{RA}$ and severe RA, values represent the mean $\pm \mathrm{SD}, \mathrm{p}<0.05$ significant, **highly significant.

The platelet count of severe RA patients was significantly higher than moderate RA patients with $p$-value $<0.001$. MPV and PDW of severe RA patients were significantly lower than moderate RA patients with p-values 0.007 and 0.012 respectively.

\begin{tabular}{|c|c|c|c|}
\hline Parameter & Group & Mean \pm SD & P value \\
\hline $\begin{array}{c}\text { Platelet count } \\
\left(\mathrm{x} 10^{9} / \mathrm{L}\right)\end{array}$ & Severe RA & $386.13 \pm 109.259$ & \multirow{2}{*}{$0.004^{* *}$} \\
\cline { 2 - 3 } & Normal Persons & $300.07 \pm 113.413$ & \\
\hline $\begin{array}{c}\text { Mean Platelet } \\
\text { Volume (fL) }\end{array}$ & Severe RA & $8.710 \pm 0.699$ & \multirow{2}{*}{$0.001^{* *}$} \\
\cline { 2 - 3 } $\begin{array}{c}\text { Platelet } \\
\text { Distribution } \\
\text { Width (fL) }\end{array}$ & Sormal Persons & $9.333 \pm 0.699$ & \\
\cline { 2 - 3 } & Normal Persons & $10.30 \pm 1.136$ & \multirow{2}{*}{$0.019^{* *}$} \\
\hline
\end{tabular}

Table 3. Comparison of Platelet Indices between Moderate Rheumatoid Arthritis and Normal Persons

$\mathrm{N}=30$ in both severe RA and normal persons, values represent the mean $\pm \mathrm{SD}, \mathrm{p}<0.05$ significant, **highly significant.

The platelet count of severe RA patients was significantly higher than normal persons with p-value 0.004. MPV and PDW of severe RA patients were significantly lower than normal persons with p-values 0.001 and 0.019 respectively.

\section{DISCUSSION}

Our study was conducted in a tertiary care centre over a period of four months. Sixty RA patients were studied of which 30 patients were with moderate disease activity and 30 patients with high disease activity according to DAS-28 score. Control group involves 30 normal individuals. There were $18 \%$ males and $82 \%$ female RA patients. There was female predominance in our study, which is similar to studies done by Isik et al (68\% females and 32\% males).[12]

DAS-28 is a disease activity measure of RA recommended for clinical use. It uses number of joints involved along with ESR or CRP values and provides a single score on continuous scale 0 - 9.4. This test has got excellent validity, reliability and responsiveness as per Anderson et al who studied various RA disease activity measures to be followed in clinical practice.[11] DAS-28 has been used in various studies to assess disease activity in RA. Yildirim et al studied the correlation of MPV and PDW with disease activity in RA using DAS-28.[10] Isik et al studied the role of platelet indices as inflammatory markers in RA using DAS-28 to divide patients under remission (below 2.6 score) and having active disease (above 2.6).[12] We also used DAS-28 scale to assess the disease activity in RA and divided patients into two categories of moderate disease activity (score between 3.2 - 5.1) and high disease activity (score > 5.1).

Circulating cellular complexes of platelets are often found in the bloodstream of patients with inflammatory conditions such as RA. Platelet-derived microparticles along with other biological agents play an important role in the development of synovitis than activated platelets themselves.[13] Laboratory studies have demonstrated that platelets exert arthritogenic properties through the activation of the collagen glycoprotein VI receptor and subsequent shedding of microparticles.[14]

Within the normal ranges of platelet count and MPV, there is an inverse correlation between platelet count and MPV and a direct correlation between MPV and megakaryocyte count. Some platelet markers including Mean Platelet Volume (MPV), a simple indicator of platelet size and activity has been investigated to be correlated with inflammation. However, platelet markers significance is not well established, and their study is not performed routinely. Mildly elevated platelet count along with decreased platelet size has been viewed as a reflection of inflammatory megakaryopoiesis and activity of RA, and also the ratio of platelets to neutrophils and lymphocytes has been suggested to reflect rheumatoid activity.[15,16]

Isik et al studied the effect of plateletcrit, MPV and PDW in 120 RA patients with active disease activity and under remission and 40 controls.[12] They found increased plateletcrit and decreased MPV and PDW in severe disease activity similar to our study.

Some studies showed that RA patients with high disease activity tend to have smaller size of platelets than those at remission. Kisacik et al found small size of platelets in RA patients at active stage, compared to it after a 2-month conventional anti-rheumatic treatment. They reported lower values of MPV in patients with active RA than controls and these values increased significantly after treatment, but remained lower than in control patients.[17] MPV in the active RA group was $9.80 \pm 0.74 \mathrm{fL}$, which was lower than $10.13 \pm$ $0.79 \mathrm{fL}$ (P-value $<0.001$ ) in the OA group. The result in the inactive RA group was $10.08 \pm 0.71 \mathrm{fL}$.[18] We got MPV of $8.710 \pm 0.699 \mathrm{fL}$ in high disease activity RA and $9.333 \pm 0.699 \mathrm{fL}$ in normal persons, which is consistent with 
studies by Kisacik et al[17] showing lower values in high disease activity RA (p-value 0.001 ).

Talukdar et al studied disease activity in rheumatoid arthritis patients using DAS-28 scale and found increased platelet count and MPV in high disease activity RA.[19] We also got increased platelet count similar to this study, but got a lower MPV in high disease activity. This study also found that patients with high DAS-28(3) score had higher MPV levels. This result is consistent with the inference drawn by previous studies done by Milovanovic $\mathrm{M}$ et al and Yazici et al, where they found a positive correlation between increased MPV and high disease activity. ${ }^{[20,4]}$ But we got a statistically significant decrease in MPV in severe RA as compared to the other 2 groups.

This increase in MPV can be explained by the fact that different cytokines (e.g. IL-6, thrombopoietin etc.) cause increased platelet production in active RA as a part of inflammatory process and these newly formed young platelets are larger and more active causing increased risk of atherosclerosis and cardiovascular disease in RA patients with high disease activity.[19-21]

Mainly studies have shown both increase and decrease in MPV in high disease activity RA. The controversy in MPV in severe RA is explained well by Gasparyan et al. According to him platelet production is regulated by maturity of thrombopoietic progenitors, different cytokines and factors such as interleukins, TNF- $\alpha$ which result in time dependent changes in platelet indices.[13] Otherwise, previous studies reported the fact that the MPV is highly dependent on the time of storage until the analysis. [4] The platelet indices have been shown to be sensitive to the differences in blood sample anticoagulation, storage temperature and delays in processing. The lack of agreement may reflect differences in the assessed pathways of platelet activation, poor laboratory standardization as well as diurnal variation of MPV in both physiological and pathological conditions. ${ }^{[22]}$

The MPV is significantly lower in both RA and Ankylosing Spondylitis (AS) patients with active disease as compared with controls.[23] Other studies have shown that MPV is correlated with clinical disease activity indices in both RA and AS patients.[17,4] Moreover, platelet indices were substantially decreased after therapy. Our results are consistent with the study by Kisacik et al and Yazici et al showing correlation with disease activity.

Kisacik et al reported that MPV was significantly decreased in RA patients compared to controls.[17] Similarly, Aktas et al reported significantly decreased MPV values in patients with nasal polyps, another inflammatory condition compared to healthy population. ${ }^{[24]}$ Boilard et al reported the important role of platelets in the course of inflammatory arthritis.[14] Literature is full of data about the relation between MPV and inflammatory conditions. Therefore, the decrease of MPV in RA is not surprising.

The possible mechanisms for reduction of MPV in RA may be that, activated platelets in response to the inflammatory processes tend to be in larger size. After their utilisation and involvement in inflammatory processes, the remaining smaller inactive platelets may cause a reduction in MPV. In addition, inflammatory cytokines in blood flow may interact with the megakaryopoiesis in bone marrow and cause production of smaller platelets, which results in decrease in MPV.
When RA is left uncontrolled the RA patient may experience joint deterioration, severe disability, decreased quality of life, the onset of co-morbidities and premature mortality. Early identification of high disease activity RA by their platelet indices will help in giving prompt treatment and control the disease.

\section{Limitation}

There were certain limitations to this study. One of the limitations of this study was the small sample size. Other measures of disease activity like IL2, TNF $\alpha$ or HLA-DRB1 alleles, which have shown good association with disease activity, could not be done in our settings. This controversial result might be due to presence of some confounding factors yet to be discovered and also due to presence of additional challenge relating to methodological issues. Due to these conflicting reports, further studies on large scale are needed to clarify the discrepancies, especially regarding MPV in future.

\section{CONCLUSION}

Significantly higher platelet count and lower Mean Platelet Volume and Platelet Distribution Width were seen in high disease activity Rheumatoid Arthritis than moderate disease activity RA and healthy controls. Thus, our study suggests that platelet count which is routinely measured in automated haematology analyser, can be considered as inflammatory marker for disease activity in Rheumatoid Arthritis. However, further studies with larger population are warranted to cross validate our findings.

\section{ACKNOWLEDGEMENT}

We like to thank Dr. A. Mahesh, Professor, Department of Rheumatology, Coimbatore Medical College Hospital, Coimbatore for his invaluable support and guidance for the research.

\section{REFERENCES}

[1] Gibofsky A. Overview of epidemiology, pathophysiology and diagnosis of rheumatoid arthritis. Am J Manag Care 2012;18(Suppl 13):S295302.

[2] www.Arthritis-india.com/Rheumatoid-Arthritis.html

[3] Van Vollenhoven RF. Sex differences in rheumatoid arthritis: more than meets the eye. BMC Medicine 2009;7:12.

[4] Yazici S, Yazici M, Erer B, et al. The platelet indices in patients with rheumatoid arthritis: mean platelet volume reflects disease activity. Platelets 2010;21(2):122-5.

[5] Avina-Zubieta JA, Choi HK, Sadatsafavi M, et al. Risk of cardiovascular mortality in patients with rheumatoid arthritis: a meta-analysis of observational studies. Arthritis Rheum 2008;59(12):1690-7.

[6] Gonzalez A, Kremers MH, Crowson CS, et al. The widening mortality gap between rheumatoid arthritis patients and the general population. Arthritis Rheum 2007;56(11):3583-7. 
[7] Fransen J, Stucki G, van Riel PLCM. Rheumatoid Arthritis Measures: Disease Activity Score (DAS), Disease Activity Score-28 (DAS28), Rapid Assessment of Disease Activity in Rheumatology (RADAR) and Rheumatoid Arthritis Disease Activity Index (RADAI). Arthritis \& Rheumatism (Arthritis Care \& Research) 2003;49(Suppl 5):S214-24.

[8] Visual DAS 28 Calculator. http://www.4sdawn.com/DAS28/.

[9] Kuter DJ. The physiology of platelet production. Stem Cells 1996;14(Suppl 1):88-101.

[10] Yildirim A, Karabiber M, Surucu GD, et al. The changes of mean platelet volume and platelet distribution width in patients with rheumatoid arthritis and their correlation with disease activity. Acta Medica Mediterranea 2015;31:1105-11.

[11] Anderson J, Caplan L, Yazdany J, et al. Rheumatoid arthritis disease activity measures: American College of Rheumatology recommendations for use in clinical practice. Arthritis Care Res (Hoboken) 2012;64(5):640-7.

[12] Isik M, Sahin H, Huseyin E. New platelet indices as inflammatory parameters for patients with rheumatoid arthritis. Eur J Rheumatol 2014;1(4):1446.

[13] Gasparyan AY, Stavropoulos-Kalinoglou A, Mikhailidis DP, et al. Platelet function in rheumatoid arthritis: arthritic and cardiovascular implications. Rheumatol Int 2011;31(2):153-64.

[14] Boilard E, Nigrovic PA, Larabee $K$, et al. Platelets amplify in inflammation in arthritis via collagendependent microparticle production. Science 2010;327(5965):580-3.

[15] Gasparyan AY, Ayvazyan L, Mikhailidis DP, et al. Mean platelet volume: a link between thrombosis and inflammation? Curr Pharm Des 2011;17(1):47-58.
[16] Fu H, Qin B, Hu Z, et al. Neutrophil- and platelet-tolymphocyte ratios are correlated with disease activity in rheumatoid arthritis. Clin Lab 2015;61(3-4):269-73.

[17] Kisacik MB, Tufan A, Kalyoncu U, et al. Mean Platelet Volume (MPV) as an inflammatory marker in ankylosing spondylitis and rheumatoid arthritis. Joint Bone Spine 2008;75(3):291-4.

[18] Kim DA, Kim TY. Controversies over the interpretation of changes of mean platelet volume in rheumatoid arthritis. Platelets 2011;22(1):79-80.

[19] Talukdar M, Barui G, Adhikari A, et al. A study on association between common haematological parameters and disease activity in rheumatoid arthritis. Journal of Clinical and Diagnostic Research 2017;11(1):EC01-EC04.

[20] Milovanovic M, Nilsson E, Järemo P. Relationships between platelets and inflammatory markers in rheumatoid arthritis. Clin Chim Acta 2004;343(12):237-40.

[21] Mathur SC, Schexneider KI, Hutchison RE. Haematopoiesis. In: McPherson RA, Pincus MR, eds. Henry's Clinical diagnosis and management by laboratory methods. 22 edn. Philadelphia: Elsevier Saunders 2011.

[22] Gasparyan AY, Sandoo A, Stavropoulos-Kalinoglou A, et al. Mean platelet volume in patients with rheumatoid arthritis: the effect of anti-TNF- $\alpha$ therapy. Rheumatol Int 2010;30(8):1125-9.

[23] Harifi G, Sibilia J. Pathogenic role of platelets in rheumatoid arthritis and systemic autoimmune diseases: perspectives and therapeutic aspects. Saudi Medical Journal 2016;37(4):354-60.

[24] Aktas G, Tekce H, Sit M. Mean Platelet Volume in nasal polyp. West Indian Medical Journal 2015;62(6):375-8. 